\title{
Immature Bone
}

National Cancer Institute

\section{Source}

National Cancer Institute. Immature Bone. NCI Thesaurus. Code C32767.

The earliest tissue to appear in embryonic development (it is the predominant bone in the developing fetus) and post fracture. The collagenous lamellae are randomly oriented and loosely intertwined. It is characterized by coarse fiber bundles approximately 30 um in diameter. 